\title{
Antibiotic Susceptibility of Stenotrophomonas maltophilia Isolated from Various Clinical Specimens
}

öz

Stenotrophomonas maltophilia, hastane enfeksiyonu etkeni olarak giderek artan sıklıkla karşılaşılan fırsatçı bir patojendir ve geniş spektrumlu antibiyotiklerin çoğuna dirençlidir. Bu çalışmada, yaklaşık beş yıllık süre boyunca izole edilmiş S. maltophilia suşlarının dağılımının ve antibiyotik duyarlııklarının incelenmesi amaçlanmıştır. Ocak 2014-Eylül 2018 tarihleri arasında çeşitli klinik örneklerden izole edilen toplam 53 S. maltophilia suşunun antibiyotiklere direnç oranları incelenmiştir. Bakteri identifikasyonu ve antibiyotik duyarIılığı için BD Phoenix 100 Otomatize Sistemi (Becton Dickinson Diagnostic Systems, Sparks, ABD) kullanılmıștır. S. maltophilia sușlarının \% 21'i poliklinik, \% 79'u yataklı servis hastalarına ait örneklerden izole edilmiştir. Yatan hastaların \% 50'sinin yoğun bakım ünitesinde tedavi gördüğü gözlenmiştir. Antibiyotik duyarlııkları sırası ile trimetoprimsülfametoksazol (TMP-SXT), levofloksasin ve seftazidim için, \% 88.6, \% 85 ve \% 30 şeklindedir. Tigesiklin minimum inhibitör konsantrasyon (MiK) değeri $2 \mathrm{mg} / \mathrm{I}$ 'nin üzerinde dirençli kabul edildiğinde tigesikline \% 83 duyarlılı saptanmıştır. Çalışmamızda, seftazidime karşı saptanan direnç nedeniyle, üçüncü kuşak sefalosporinlerin hastanemizde S. maltophilia'nın ampirik tedavisinde kullanılamayacağı sonucuna varılmıștır. TMP-SXT ve levofloksasin direncimiz henüz korkulacak boyutlarda olmamasına rağmen artan direnç oranları açısından dikkat edilmesi gerektiği görülmüştür.

Anahtar kelimeler: antibiyotik duyarlılık, levofloksasin, seftazidim, Stenotrophomonas maltophilia, trimetoprim-sulfametoksazol, tigesiklin

\begin{abstract}
Stenotrophomonas maltophilia is an opportunistic emergent pathogen causing hospital-acquired infections and it is resistant to majority of the broad spectrum antibiotics. The aim of this study was to investigate the distribution and antimicrobial susceptibility patterns of S.maltophilia strains isolated in approximately five years. In this study; a total of 53 S.maltophilia strains, isolated from various clinical specimens between January 2014-September 2018 were investigated in terms of antibiotic resistance rates. The isolates were identified and antibiotic susceptibility tests performed by BD Phoenix 100 automated system (Becton Dickinson Diagnostic Systems, Sparks, USA). Out of 53 S.maltophilia strains, $21 \%$ were isolated from outpatient clinics and $79 \%$ from hospitalized patients. And $50 \%$ of hospitalized patients were admitted to the Intensive Care Unit. Antibiotic susceptibilities to trimetoprim-sulfametoksazol (TMP-SXT), levofloxacin and ceftazidim were; $88.6 \%, 85 \%$ and $30 \%$, respectively. When considering the MIC value $>2 \mathrm{ug} / \mathrm{ml}$ resistant for tigecycline; $83 \%$ of the isolates were susceptible. In our study, it was concluded that third-generation cephalosporins cannot be used in the empirical treatment of S.maltophilia in our hospital due to the detection of the resistance to ceftazidime. Although TMP-SXT and levofloxacin resistance are not yet to be feared, increased resistance rates should be taken into consideration.
\end{abstract}

Keywords: antibiotic susceptibility, ceftazidime, levofloxacin, Stenotrophomonas maltophilia, trimethoprim-sulfamethoxazole, tigecycline
Alındığı tarih: 22.03 .2019

Kabul tarihi: 25.07.2019

Yayın tarihi: 30.08 .2019

Berrin Uzun

İmir Katip Çelebi Üniversitesi Atatürk EAH

Tıbbi Mikrobiyoloji Kliniği İzmir - Türkiye

berrinuzun@gmail.com ORCID: 0000-0001-9115-5910

Ç. Arabacı 0000-0003-0050-3225 S.B.Ü. Okmeydanı EAH Tıbbi Mikrobiyoloji Laboratuvarı istanbul - Türkiye

Ö. Yanılmaz 0000-0003-3847-7288 Marmara Üniversitesi Istanbul Pendik EAH Tıbbi Mikrobiyoloji Kliniği istanbul - Türkiye 


\section{Giriş̧}

Illk kez 1943 yılında plevral sıvıdan izole edilen, daha önce Pseudomonas maltophilia veya Xanthomonas maltophilia olarak adlandırılan Stenotrophomonas maltophilia, doğada, sularda, toprakta, bitkilerde ve hayvanlarda bulunabildiği gibi insanlarda da floranın bir üyesi olarak ortaya çıkabilen, fırsatçı enfeksiyonlar açısından önemi artan nonfermentatif Gram negatif bir basildir ${ }^{(17)}$.

S.maltophilia enfeksiyonları, özellikle kateteri bulunan, mekanik solunum cihazına bağlı yoğun bakım hastalarında ve immünsüpresif hastalarda görülmektedir. Bununla birlikte uzun süreli hastanede yatış ve geniş spektrumlu antibiyotik kullanımı bu mikroorganizmaya bağlı enfeksiyon riskini arttırmaktadır(22). Biyofilm oluşturabilme özelliği nedeniyle de özellikle kateter ilişkili enfeksiyonlarda, bakteriyemi ve pnömonilerde etken olarak karşımıza çıkmaktadır ${ }^{(1,22)}$.

S.maltophilia, beta-laktamaz, aminoglikozid asetil transferaz ve eritromisini inaktive eden enzim veatım pompalarıkodlayangenlergibimekanizmaların varlığıyla aminoglikozidler, beta-laktamlar, tetrasiklinler gibi birçok antibiyotiğe intrensek direnç gösterir. Horizontal geçişle gram pozitif bakterilerden bile antibiyotik direnç genleri alabilmesi, karbapenemler dahil pek çok geniş spektrumlu antibiyotiğe de direnç gösterebilmesi nedeniyle ampirik tedavi seçeneklerini oldukça kısıtlayarak tedavi sorunlarına sebep olmaktadır ${ }^{(1,17)}$.

Trimetoprim-sülfametoksazol (TMP-SXT) bu patojen için tercih edilen antimikrobiyal ajandır ancak bakteriyostatiktir. Son yıllarda farklı coğrafi bölgelerde yapılan çalışmalar, hem yüksek etki gücü hem de kullanılabilen hasta profilinin genişliği nedeniyle tedavide ilk tercih olarak önerilen bu ajana karşı direnç geliştiğini ve bu direncin yıllar içerisinde arttığını göstermektedir ${ }^{(10,11,17)}$. Direnç özelliklerinin belirlenmesine yönelik epidemiyolojik çalışmalar ampirik tedavide klinisyene yol göstermesi açısından yararlıdır.

Çalışmamız, S.maltophilia izolatlarının değişen direnç oranlarının belirlenerek hastanemiz tedavi protokollerinin düzenlenebilmesi ve ülkemiz sürveyans verilerine katkıda bulunulması amacıyla gerçekleştirilmiştir.

\section{GEREÇ VE YÖNTEM}

Ocak 2014-Eylül 2018 tarihleri arasında Sağlık Bilimleri Üniversitesi Okmeydanı Eğitim ve Araştırma Hastanesi Tıbbi Mikrobiyoloji Laboratuvarı'nda, yatarak ve ayaktan tedavi edilen hastaların çeşitli klinik örneklerinden izole edilen S.maltophilia suşları çalışmaya dahil edilmiştir. Birden fazla örneğinde üreme olan hastalarnın yalnızca bir suşu çalışmaya dahil edilmiştir. Tekrar eden örnekler çalışmaya alınmamış, aynı hastaya ait farklı örnekler duyarlıık oranları saptanırken dahil edilmemiştir.

Kan kültürleri BACTEC 9240 (Becton Dickinson, Diagnostic Instrument System, Sparks, USA) tam otomatik kan kültür cihazında çalışıımıştır. Otomatize kan kültür cihazında üreme saptanan şişelerden Mac Conkey, çikolata ve \% 5 koyun kanlı agarlara pasajları yapılmıştır. İdrar, doku-apse, trakeal aspirat, kateter ucu, steril sıvıların kültürleri materyaline göre ve usulüne uygun olarak standart mikrobiyolojik teknikler kullanılarak değerlendirilmiştir(6).

Etken olduğu düşünülen koloniler, Phoenix ${ }^{\mathrm{TM}}$ 100 (Becton Dickinson, Diagnostic Instrument System, Sparks, USA) otomatize sistemiyle tür düzeyinde tanımlanmış ve antibiyotik duyarlılıkları çalışılmıştır. Antibiyotik duyarlılıkları Ocak 2014Aralık 2015 yıllarında Clinical and Laboratory Standards Institute $(\mathrm{CLSI})^{(3)}$ önerileri doğrultusunda A grubu antibiyotik olarak TMP-SXT, B grubu antibiyotik olarak levofloksasin, seftazidim için; Ocak 2016-Haziran 2018 yıllarında The European Committee on Antimicrobial Susceptibility Testing (EUCAST) $^{(6)}$ önerileri doğrultusunda TMP-SXT için değerlendirilmiştir. Levofloksasin ve seftazidim için klinik sınır değerler EUCAST önerilerinde bulunmamasına rağmen çalışılmaya devam edilmiş, minimum inhibitör konsantrasyon (MiK) değerleri belirlenmiş; ancak, kliniğe bildirilmemiştir. Tigesiklinin klinikte kullanıldığı ve Mik değerlerine göre değerlendirilen çalışmalar ${ }^{(2,20)}$ da dikkate alınarak ve 
enfeksiyon kliniklerin talebi nedeniyle belirlenmiş klinik sınır değerler standartlarda bulunmamasına rağmen otomatize sistemden alınan Mik değerleri de çalışmamızda değerlendirilmiş, tigesiklin için MiK>2 $\mathrm{mg} / \mathrm{l}$ olduğunda dirençli kabul edilmiştir.

\section{BULGULAR}

Çalışma süresi içerisinde 53 farklı hastaya ait 71 örnekte S.maltophilia üremesi olmuştur. Çalışmaya her hastadan tek izolat alınmış, dahil edilen 53 S.maltophilia suşunun \% 21'i (11/53) poliklinik, \% 79’u (42/53) yatan hastalara ait örneklerden izole edilmiştir. Poliklinik hastalarının \% 45.5’i (5/11) plastik cerrahi, \% 27.3'ü (3/11) acil servis, \% 18.2'si (2/11) üroloji, \% 9’u (1/11) cildiye polikliniğine

Tablo 1. S.maltophilia izole edilen yatan hastaların kliniklere göre dağılımı.

\begin{tabular}{lcc}
\hline Klinikler & $\mathbf{n}$ & $\%$ \\
\hline Yoğun Bakım Ünitesi & 21 & 50 \\
Hematoloji & 4 & 9.5 \\
Enfeksiyon Hastalıkları & 4 & 9.5 \\
Dahiliye & 3 & 7.0 \\
Onkoloji & 2 & 4.8 \\
Genel Cerrahi & 2 & 4.8 \\
Çocuk & 2 & 4.8 \\
Nöroloji & 1 & 2.4 \\
Göz Hastalıkları & 1 & 2.4 \\
Üroloji & 1 & 2.4 \\
Beyin Cerrahisi & 1 & 2.4 \\
\hline Toplam & & 100 \\
\end{tabular}

Tablo 2. S.maltophilia izole edilen klinik örneklerin dağılımı.

\begin{tabular}{lcc}
\hline Örnek Yeri & $\mathbf{n}$ & $\%$ \\
\hline Kan kültürü & 34 & 48 \\
Doku-apse & 13 & 18 \\
İdrar & 11 & 16 \\
Trakeal aspirat & 10 & 14 \\
Kateter ucu & 2 & 3 \\
Beyin omurilik sıvısı & 1 & 1 \\
\hline Toplam & 71 & 100
\end{tabular}

başvuran hastalardan oluşmuştur. Yatan hastaların \% 50'sinin (21/42) yoğun bakım ünitesinde oldukları gözlenmiştir. Hastaların servislere dağılımları Tablo 1'de verilmiştir. Hastaların \% 64'ünün (34/53) erkek, \% 36'sının (19/53) kadın; yaş ortalamalarının erkeklerde 48 (11-83), kadınlarda 60 (0-92) olduğu saptanmıştır. Elli üç hastanın \% 73.5'i sırasıyla malignite, bronko-pulmoner displazi, nörolojik yaralanma, diyabet, böbrek yetmezliği, cerrahi öyküsü gibi tanılarla takip edildiği görülmüştür. S.maltophilia üremesi gözlenen 71 örneğin \% 48'inin $(n=34)$ kan olduğu belirlenmiş ve örnek dağılımı Tablo 2'de özetlenmiştir. Antibiyotik duyarlılık oranları Tablo 3'te verilmiş, en etkili antimikrobiyal ajan TMP-SXT (\% 88.6) olmuş, onu levofloksasin (\% 85) izlemiştir. Tigesiklin için \%83 duyarlılık saptanmıştır ${ }^{(2,20)}$. Tigesiklin MiK değerleri 9 suşta $<1$ $\mathrm{mg} / \mathrm{l}, 15$ suşta $1 \mathrm{mg} / \mathrm{l}, 20$ suşta $2 \mathrm{mg} / \mathrm{l}, 9$ suşta ise $>2$ $\mathrm{mg} / \mathrm{l}$ bulunmuştur.

Tablo 3. S.maltophilia suşlarının antibiyotik duyarlııkları.

Antibiyotik

\begin{tabular}{|c|c|c|c|c|c|c|c|c|}
\hline \multirow[b]{2}{*}{ Yıllar/ Suş Sayısı } & \multicolumn{2}{|c|}{$\begin{array}{c}\text { Trimetoprim- } \\
\text { sülfametoksazol }\end{array}$} & \multicolumn{2}{|c|}{ Levofloksasin } & \multicolumn{2}{|c|}{ Seftazidim } & \multicolumn{2}{|c|}{ Tigesiklin } \\
\hline & $\mathrm{n}$ & $\%$ & $n$ & $\%$ & $\mathrm{n}$ & $\%$ & $\mathbf{n}$ & $\%$ \\
\hline 2014 / 3 & 2 & 66.7 & 3 & 100 & 2 & 66.7 & 3 & 100 \\
\hline 2015 / 10 & 9 & 90 & 8 & 80 & 4 & 40 & 9 & 90 \\
\hline 2016 / 18 & 16 & 88.9 & 16 & 88.8 & 5 & 27.7 & 16 & 88.8 \\
\hline 2017 / 12 & 11 & 91.6 & 10 & 83.2 & 1 & 8 & 8 & 66.7 \\
\hline 2018 / 10 & 9 & 90 & 8 & 80 & 4 & 40 & 8 & 80 \\
\hline Toplam / 53 & 47 & 88.6 & 45 & 85 & 16 & 30 & 44 & 83 \\
\hline
\end{tabular}




\section{TARTIŞMA}

Ülkemizde sağlık hizmetiyle ilişkili enfeksiyonlardan S.maltophilia enfeksiyonları artan sıklıklarla karşımıza çıkmaktadır ${ }^{(8,15,19)}$. SENTRY antimikrobiyal sürveyans çalışmasında Latin Amerika'da ilk on pnömoni etkeninden biri olarak tanımlanırken, SMART raporunda Asya Pasifik bölgesinde intraabdominal enfeksiyonlarda ilk dört etken arasında bildirilmiştir ${ }^{(8,15,19)}$.

Son yıllarda immünsüpresif hasta sayısında artma, hastanede yatış süresinin uzaması, yoğun bakım ünitelerinde yatış, kronik solunum yolu hastalıkları (kistik fibrozis gibi), geniş spektrumlu antibiyotikkullanımı, malignansiler, immünsüpresyon, mukokütanöz bariyerin bozulması (mekanik ventilasyon, kateter girişimleri, trakeotomi, periton diyalizi vb.), geçirilmiş cerrahi öyküsü, prematürite gibi nedenler S.maltophilia enfeksiyonlarının risk faktörleri olarak tanımlanmıştır ${ }^{(1)}$. Çalışmamızda izole edilen S.maltophilia izolatlarının \% 79'u yatan hastalara ait örneklerden izole edilmiştir. Risk faktörleri arasında yer alan hastanede yatış $S$. maltophilia enfeksiyonu için beklenen bir risk olmasına rağmen azımsanmayacak ölçüde poliklinik hastalarına ait örneklerde de izolasyon mevcuttur. Ülkemizde yapılmış çalışmalarda, istatistiksel olarak incelenmemiş olmakla birlikte yıllarına göre \% 4.5, \% 18.5 gibi artan oranlarda poliklinik hastalarında izolasyon sıklığının artışı dikkat çekmektedir ${ }^{(9,10)}$. Çalışmamızda bu bulguları doğrular şekilde \% 21 oranıyla bu yayınlardan biraz daha yüksek oranda izolasyon gerçekleştirilmiştir. Farklı bölgelerden ve farklı hasta profillerine sahip hastanelerde poliklinik hastalarında izlenen izolasyon artışı; toplum kaynaklı enfeksiyonlarda artış olabileceği sorusunu akla getirmekte, bununla ilgili sebep analizli çok merkezli bir çalışma yapılması gerektiğini düşündürmektedir.

S.maltophilia enfeksiyonlarının risk faktörleri arasında sayılan sebeplerle uyumlu olarak çalışmamızda incelenen hastaların yarısı yoğun bakım hastaları, immünsüpresif hastaların takip edildiği hematoloji, dahiliye, onkoloji gibi kliniklerde tedavi gören hastalara ait örneklerde izole edilmiştir. Yine bu hastaların dörte üçünün de (\% 73.5) literatürle uyumlu olarak bronkopulmoner displazi, malignensi, diabet, nörolojik hastalıklar gibi fırsatçı enfeksiyona zemin hazırlayan nitelikte tanılar olduğu da görülmektedir.

Ana klinik tablo bakteriyemi/sepsis olup solunum yolu enfeksiyonları da sıklıkla görülmektedir. Bunların dışında idrar yolu enfeksiyonu, yumuşak doku enfeksiyonları, daha nadir görülse de endokardit, göz enfeksiyonları, menenjit gibi farklı odaklarda enfeksiyonlara neden olabilir(21). Hastane enfeksiyonlarının kaynağı tıbbi ekipmanlar ve kontamine su sistemidir(2). Biyofilm oluşturması nedeniyle bu enfeksiyonların ana kaynağının solunum yolu, santral ve üriner kateterler olduğu yapılan çalışmalarda gösterilmiştir(1). Çalışmamızda S.maltophilia izolatlarının \% 48'i hemokültürden, \% 18'i yumuşak dokudan, \% 16'sı idrardan, \% 14'ü trakeal aspirattan ve bir izolat beyin omurilik sıvısından izole edilmiştir. S.maltophilia'ya bağlı enfeksiyon oranlarında azalma sağlanabilmesi için özellikle risk faktörlerine sahip hasta gruplarında kolonizasyonu engelleyici önlemlerin daha sıkı alınması gerektiği çalışmamızla da desteklenmiştir.

S.maltophilia enfeksiyonlarının tedavisinde ilk tercih edilmesi gereken ilacın TMP-SXT olduğu bildirilmekle birlikte, bu ajana karşı da direnç geliştiği yönünde raporlar giderek artmaktadır. Çalışmamızda 53 hastaya ait S.maltophilia izolatı incelenmiş ve \% 11.4'ünün TMP-SXT'ye dirençli olduğu görülmüştür. Ülkemizde gerçekleştirilen çalışmalarda TMP-SXT direncini \% 4.8 ile \% 15.2 aralığında tespit etmişlerdir ${ }^{(9,10,14,17,21,22)}$. Yurtdışı çalışmalarda TMP-SXT direncini Meksika'da(11) \% 25; Çin'de(12) \% 38.7, Fransa'da(5) \% 5 olarak belirtmişlerdir.

$\mathrm{CLSI}^{(3)}$, antibiyotik duyarlılığının test edilmesinde beta-laktamlardan seftazidim çalışılmasını önermekte, EUCAST ${ }^{(6)}$ ise hiçbir beta-laktam ajanın çalışılmasını önermemektedir. Yurtiçi çalışmalarda, seftazidim direnci \% 77.6 ile \% 78 aralığında saptanmıştır ${ }^{(9,14,21)}$. Seftazidim direncini yurtdışı çalışmalarda Fransa'da \% 70, Kuzey Amerika'da \% 34.9, Asya-Pasifik bölgesinde de \% 53.5 olarak tespit etmişlerdir ${ }^{(5,7)}$. Çalıştığımız S.maltophilia suşlarında en yüksek direnç 
\% 70 ile seftazidime karşı saptanmıştır. Bu değerle hastanemizde beta-laktam antibiyotiklerin S.maltophilia enfeksiyonlarının tedavisinde kullanılmasının uygun olmadığı sonucuna varılmıştır.

Florokinolon grubu antibiyotikler, özellikle S.maltophilia gibi çoklu ilaç direnci geliştiren nonfermentatif bakterilere bağlı enfeksiyonlarda önemli tedavi alternatifleri arasında sayılmaktadır. Trovafloksasin, klinafloksasin, grepafloksasin, gatifloksasin, moksifloksasin, levofloksasin gibi yeni kuşak kinolonların tedavide siprofloksasinden 4-8 kat daha etkili oldukları bildirilmektedir ${ }^{(23)}$. Corlouer ve ark. ${ }^{(5)}$ siprofloksasine karşı Fransa'da \% 17 direnç saptarken levofloksasin direnç oranı yurtdışı çalışmalarda Tayvan'da ${ }^{(23)} \%$ 8; Meksika'da ${ }^{(11)} \%$ 2.6; Çin'de ${ }^{(12)} \% 19.6$ tespit etmişlerdir. Asya Pasifik bölgesinde gerçekleştirilen Antimikrobiyal Direnç Eğilimleri İzleme Çalışması'nda intraabdominal enfeksiyonlarla ilişkili S.maltophilia izolatlarında \% 26.5 direnç oranıyla levofloksasine direnç geliştiği gözükmektedir ${ }^{(15)}$. Fransa'daki bir çalışmada, levofloksasin direnci \% 30.4 bulunmuştur(23). Macaristan'daki çalışmada S.maltophilia izolatlarının sadece \% 37'si levofloksasin veya moksifloksasine duyarlı bulunmuştur(13).

Ülkemizde ise levofloksasin için \% 5 ile \% 23.7 aralığında direnç bulunurken, siprofloksasin direncini \% 61 saptanmıştır ${ }^{(9,10,14,21,22)}$. Görüldüğü üzere S.maltophilia'ya karşı TMP-SXT'den sonraki alternatif olan kinolona karşı direncin farklı coğrafik bölgelerde, aynı bölgedeki farklı hastanelerde ve hatta aynı hastaneden farklı zamanlarda tespit edilen antibiyotik dirençlerinin değişiklik göstermektedir. Çalışmamızda \% 15 gibi ülkemiz verilerinin ortalamasından yüksek oranda direnç saptanmıştır. Levofloksasinin tedavide alternatif olamayacağını, TMP-SXT direncinin de azımsanmayacak oranda saptanması nedeniyle TMP-SXT'ye alternatif olabilecek bu ajanın hastanemiz suşları için daha kısıtlı kullanılması gerektiğini düşündürmektedir.

Bu veriler ışığında S.maltophilia'nın gösterdiği antibakteriyel direncin ve tedavide kullanılabilecek antimikrobiyallerin kısıtıılığının, hem dünya da hem de ülkemizde önemli bir problem olduğu, tek başına ya da kombine olarak kullanılmak üzere yeni antibiyotiklerin geliştirilmesine intiyaç olduğu görülmektedir. Tigesiklin ve levofloksasin kombinasyon tedavilerinde kullanılmakta, özellikle kistik fibrozis hastalarında umut vaad edici bulunmaktadır ${ }^{(7,18)}$. S.maltophilia enfeksiyonları için 2010 yılında tigesiklinin etkili olduğu rapor edilmiştir ${ }^{(18)}$. Çok merkezli başka bir çalışmada çeşitli klinik izolatlardan izole edilen S.maltophilia izolatlarına Avrupa, Kuzey Amerika, Asya ve Pasifik Bölgesinde ve Latin Amerika'da tigesiklinin en etkili antibiyotik olduğu bildirilmiştir ${ }^{(7)}$. Çin'den bildirilen çalışmada \% 16.7 oranında tigesiklin direnci bildirilmiş, TMP-SXT'ye dirençli saptanan tüm suşlara tigesiklin etkili bulunmuştur ${ }^{(24)}$. Ancak 2015 yılında Fransa'da gerçekleştirilen deneysel çalışmada tigesiklin ve levofloksasinin monoterapide etkin bir ilaç olamayacağı bildirilmiştir ${ }^{(23)}$. Macaristan'daki çalışmada, suşların hepsi siprofloksasin, tigesiklin, seftazidime ve kolistine dirençli bulunmuştur ${ }^{(13)}$. Çalışmamızdaki suşlarda saptanan \% 17 oranındaki tigesiklin direnci, riskli hasta gruplarında tercih edilen tigesikline karşı da dikkatli olunması gerektiğini düşündürmüştür.

Özellikle riskli hasta gruplarında hayati tehdit eden enfeksiyonlarda kombinasyon tedavileri tercih edilmektedir(24). Tigesiklinin, kolistin ve amikasinle sinerjistik etkili olduğu bildirilmiştir ${ }^{(18)}$. Aynı şekilde tikarsilin-klavulanatın aztreonam, kolistin ve levofloksasinle kombine kullanımlarının etkili olduğu çeşitli çalışmalarda gösterilmiştir ${ }^{(16)}$. Çalışmamızda kombinasyon terapileriyle ilgili veri bulunmamaktadır. Ancak EUCAST standartlarında yer almayan tigesiklin, tikarsilin-klavulanat, levofloksasin, seftazidim gibi özellikle sinerjistik etkinliğinden yararlanılabilecek ajanların antibiyotik duyarlılıklarının belirlenmesi gerektiğinde kullanılmak üzere çalışıması önemlidir.

Sonuç olarak, çalışmamızda seftazidime karşı saptanan direnç bu ajanın hastanemizde alternatif tedavi seçeneği olarak kullanılamamasına neden olmuştur. TMP-SXT ve levofloksasin direncimiz henüz korkulacak boyutlarda olmamasına rağmen artan direnç oranları açısından dikkat edilmelidir. S. maltophilia önemli bir fırsatçı patojendir ve birçok 
antibiyotiğe karşı intrensek direnç nedeniyle tedavisi oldukça güçtür. Sağlık çalışanlarının artan sıklıkla karşımıza çıkan S.maltophilia'ya karşı daha fazla farkındalık geliştirmesi, nemli yüzeylere kolonize olabilen ve suyun ortak kirleticisi olabilen bu ajana karşı koruyucu sağıı önlemlerine dikkat etmeleri gerekliliği daha da önem kazanmıştır. Ayrıca, değişen direnç oranları nedeniyle merkezlerin sürveyans verilerini aktif olarak takip etmelerinin önemli olduğu görülmektedir.

Çıkar Çatışması: Yazarlar tarafından herhangi bir çıkar çatışması bildirilmemiştir.

Conflict of Interest: No conflict of interest was declared by the authors.

\section{KAYNAKLAR}

1. Brooke JS. Stenotrophomonas maltophilia: an emerging global opportunistic pathogen. Clin Microbiol Rev. 2012;25(1):2-41. https://doi.org/10.1128/CMR.00019-11

2. Brooke JS. New strategies against Stenotrophomonas maltophilia: a serious worldwide intrinsically drugresistant opportunistic pathogen. Expert Rev. Anti Infect. Ther. 2014;12(1):1-4. https://doi.org/10.1586/14787210.2014.864553

3. Clinical and Laboratory Standards Institute. Performance standards for antimicrobial susceptibility testing. Twenty-fourth informational supplement update. CLSI document M100-S24. Clinical and Laboratory Standards Institute, Wayne, PA (2014).

4. Clinical Microbiology Procedures Handbook 3rd ed. / Third Edition and 2007 update, Lynne S. Garcia. ISBN- 13: 978-1-5558 1-527-1.

5. Corlouer C, Lamy $B$, Desroches $M$ et al. Stenotrophomonas maltophilia healthcareassociated infection: identification of two main pathogenic genetic backgrounds. J Hosp Infect. 2017;96:183-8

https://doi.org/10.1016/j.jhin.2017.02.003

6. EUCAST. EUCAST Clinical Breakpoint TableVersion 6.0,Valid From 2016-01-01. Basel: EUCAST, 2016. http://www.eucast.org/clinical_breakpoints/.

7. Farrell DJ, Sader HS, Jones RN. Antimicrobial susceptibility of a worldwide collection of Stenotrophomonas maltophilia isolates tested against tigecycline and agents commonly used for $\mathrm{S}$. maltophilia infections. Antimicrob Agents Chemother. 2010;54(6):2735-7. https://doi.org/10.1128/AAC.01774-09

8. Gales AC, Castanheira M, Jones RN, Sader HS. Antimicrobial resistance among Gram-negative bacilli isolated from Latin America: results from SENTRY Antimicrobial Surveillance Program (Latin America, 2008-2010). Diagn Microbiol Infect Dis. 2012;73(4):354-60.

https://doi.org/10.1016/j.diagmicrobio.2012.04.007

9. Güzelant $A$, Kaya $M$, Güvenç $H i$ ve ark. Çeşitli klinik örneklerden beş yılda izole edilen Stenotrophomonas maltophilia suşlarının dağılımı ve antimikrobiyal duyarlılıkları. Türk Mikrobiyol Cem Derg. 2014;44(2): 75-9.

10. Hazırolan G, Araz H, Çelikbaş AK, Aksu N. Klinik örneklerden izole edilen Stenotrophomanas maltophilia suşlarının trimetoprim-sülfametoksazol ve levofloksasin direncinde belirgin artış var (20082016). Türk Mikrobiyol Cem Derg. 2018;48(2):13440

https://doi.org/10.5222/TMCD.2018.134

11. Herrera-Heredia SA, Pezina-Cantú C, Garza-González $E$, et al. Risk factors and molecular mechanisms associated with trimethoprim-sulfamethoxazole resistance in Stenotrophomonas maltophilia in Mexico. J Medical Microbiol. 2017;66(8):1102-9 doi:10.1099/jmm.0.000550 https://doi.org/10.1099/jmm.0.000550

12. Hu LF, Chen GS, Kong $\mathrm{QX}$ et al. Increase in the prevalence of resistance determinants to trimethoprim/sulfamethoxazole in clinical Stenotrophomonas maltophilia isolates in China. PLoS One. 2016;11:e0157693. https://doi.org/10.1371/journal.pone.0157693

13. Juhász $\mathrm{E}$, Pongrácz J, Iván $\mathrm{M}$, Kristóf $\mathrm{K}$. Antibiotic susceptibility of sulfamethoxazole-trimethoprim resistant Stenotrophomonas maltophilia strains isolated at a tertiary care centre in Hungary. Acta Microbiol Immunol Hung. 2015;62(3):295-305 https://doi.org/10.1556/030.62.2015.3.7

14. Kandemir I, Özcan N, Alanbayı Ü, Bozdağ H, Akpolat N, Gül K. Klinik örneklerden izole edilen Stenotrophomonas maltophilia suşlarının dağılımı ve antibimikrobiyal duyarlılıkları. Dicle Tıp Derg. 2016;43(2):237-40.

15. Liu YM, Chen YS, Toh HS, et al. In vitro susceptibilities of non-enterobacteriaceae isolates from patients with intra-abdominal infections in the Asia-Pacific region from 2003 to 2010: Results from the study for monitoring antimicrobial resistance trends (SMART). Int J Antimicrob Agents. 2012;40(Suppl):S11-7. 
https://doi.org/10.1016/S0924-8579(12)70004-3

16. Milne KEN, Gould IM. Combination antimicrobial susceptibility testing of multidrug-resistant Stenotrophomonas maltophilia from cystic fibrosis patients. Antimicrob Agents Chemother. 2012;56(8): 4071-7.

https://doi.org/10.1128/AAC.00072-12

17. Özkaya E, Aydın F, Bayramoğlu G, Buruk CK, Sandallı C. Klinik örneklerden izole edilen trimetoprimsülfametoksazole dirençli Stenotrophomonas maltophilia suşlarında integron, sul1-2 ve $\mathrm{dfr}$ genlerinin araştırılması. Mikrobiyol Bul. 2014;48(2): 201-12.

https://doi.org/10.5578/mb.7262

18. Parkins MD, Elborn JS. Newer antibacterial agents and their potential role in cystic fibrosis pulmonary exacerbation management. J Antimicrob Chemother. 2010;65(9):1853-61.

https://doi.org/10.1093/jac/dkq245

19. Safdar A, Rolston KV. Stenotrophomonas maltophilia: changing spectrum of a serious bacterial pathogen in patients with cancer. Clin Infect Dis. 2007;15;45(12): 1602-9.

https://doi.org/10.1086/522998

20. Togan T, Özden HT, Azap Ö. Stenotrophomonas maltophilia suşlarına tigesiklin ve kolistinin in vitro duyarlılı̆̆. Flora. 2018;23(1):25-30. https://doi.org/10.5578/flora.43431

21. Türkdağı $\mathrm{H}$, Arslan $U$, Tuncer i. Kan kültürlerinden izole edilen Stenotrophomonas maltophilia suşlarının antibiyotik direnci. ANKEM Derg. 2011;25(1):27-30.

22. Usta E, Eroğlu C, Yanık K, Karadağ A, Güney AK, Günaydın M. Klinik Stenotrophomonas maltophilia izolatlarında sınıf 1, 2, 3 integron varlığının ve antibiyotik direnci ile ilişkilerinin araştırılması. Mikrobiyol Bul. 2015;49(1):35-46. https://doi.org/10.5578/mb.8459

23. Wei C, Ni W, Zhao J, Cui J. A Monte Carlo pharmacokinetic/pharmacodynamic simulation to evaluate the efficacy of minocycline, tigecycline, moxifloxacin, and levofloxacin in the treatment of hospital-acquired pneumonia caused by Stenotrophomonas maltophilia. J Infect Dis. 2015;47(12):846-51. https://doi.org/10.3109/23744235.2015.1064542

24. Wei C, Ni W, Cai X, Zhao J, Cui J. Evaluation of trimethoprim/sulfamethoxazole (SXT), minocycline, tigecycline, moxifloxacin, and ceftazidime alone and in combinations for SXT susceptible and SXT-resistant Stenotrophomonas maltophilia by in vitro time-kill experiments. PLoS One. 2016;21:1-9. https://doi.org/10.1371/journal.pone.0152132

25. Zhanel GG, Fontaine $\mathrm{S}$, Adam $\mathrm{H}$, et al. A review of new fluoroquinolones: focus on their use in respiratory tract infections. Treat Respir Med. 2006;5(6):437-65.

https://doi.org/10.2165/00151829-200605060-00009 